\title{
Copper(II) Complexes of L-Arginine as Netropsin Mimics Showing DNA Cleavage Activity in Red Light
}

\author{
Ashis K. Patra, ${ }^{\dagger}$ Tuhin Bhowmick, ${ }^{\ddagger}$ Sovan Roy, ${ }^{\dagger}$ Suryanarayanarao Ramakumar, ${ }^{\ddagger}$ \\ and Akhil R. Chakravarty ${ }^{*} \dagger$ \\ ${ }^{\dagger}$ Department of Inorganic and Physical Chemistry, and ${ }^{\ddagger}$ Bioinformatics Center, \\ Department of Physics, Indian Institute of Science, Bangalore 560 012, India
}

Supporting Information (Revised) 


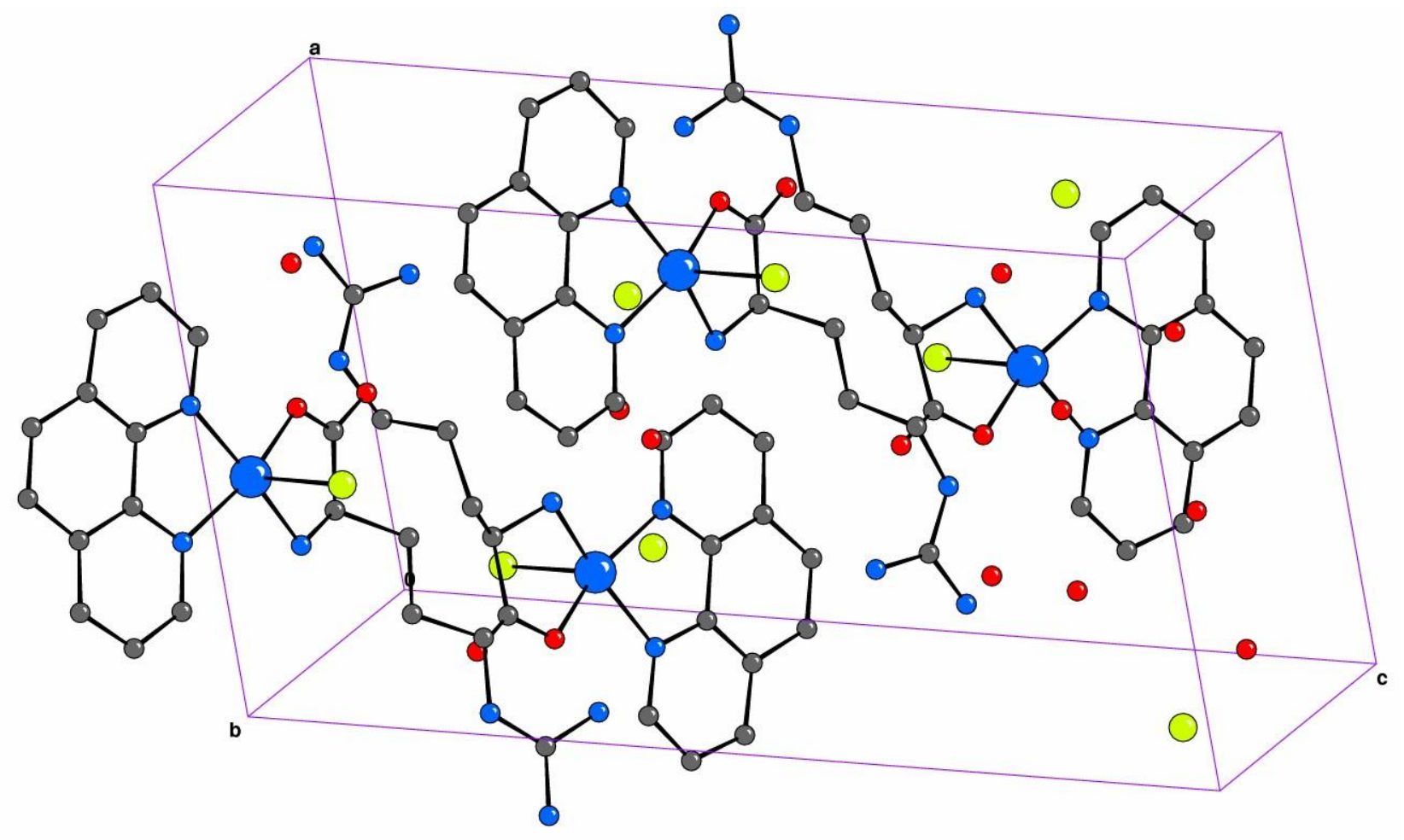

Figure S1. Unit cell packing diagram of $[\mathrm{Cu}(\mathrm{L}-\mathrm{arg})(\mathrm{phen}) \mathrm{Cl}] \mathrm{Cl} \cdot 2.5 \mathrm{H}_{2} \mathrm{O}\left(3 \cdot 2.5 \mathrm{H}_{2} \mathrm{O}\right)$. 


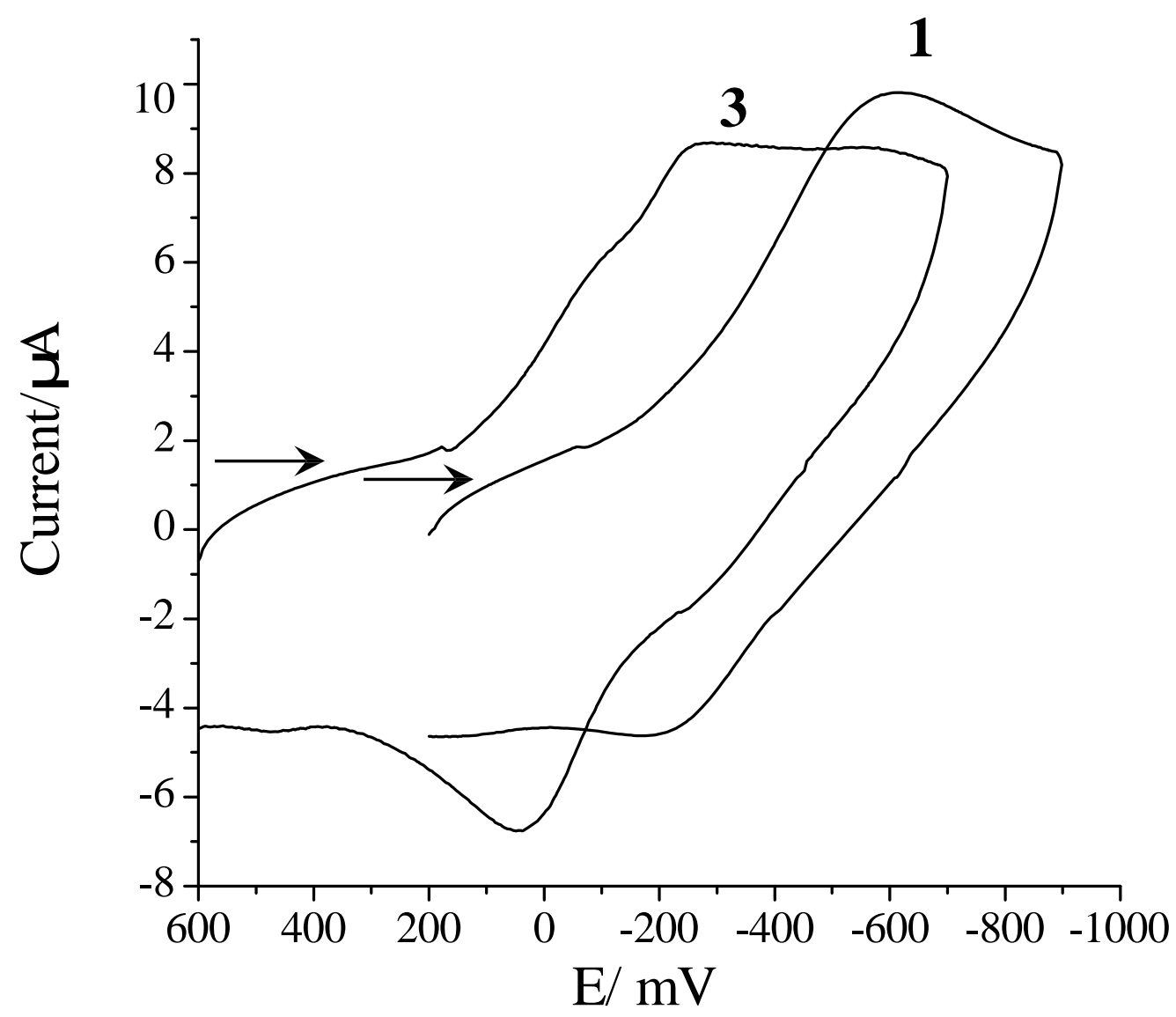

Figure S2. Cyclic voltammetric responses of $\left[\mathrm{Cu}(\mathrm{L}-\arg )_{2}\right]^{2+}(\mathbf{1})$ and $[\mathrm{Cu}(\mathrm{L}-$ $\arg )($ phen $) \mathrm{Cl}]^{+}(3)$ at $50 \mathrm{mV} \mathrm{s}^{-1}$ scan rate in DMF/0.1 M TBAP. 


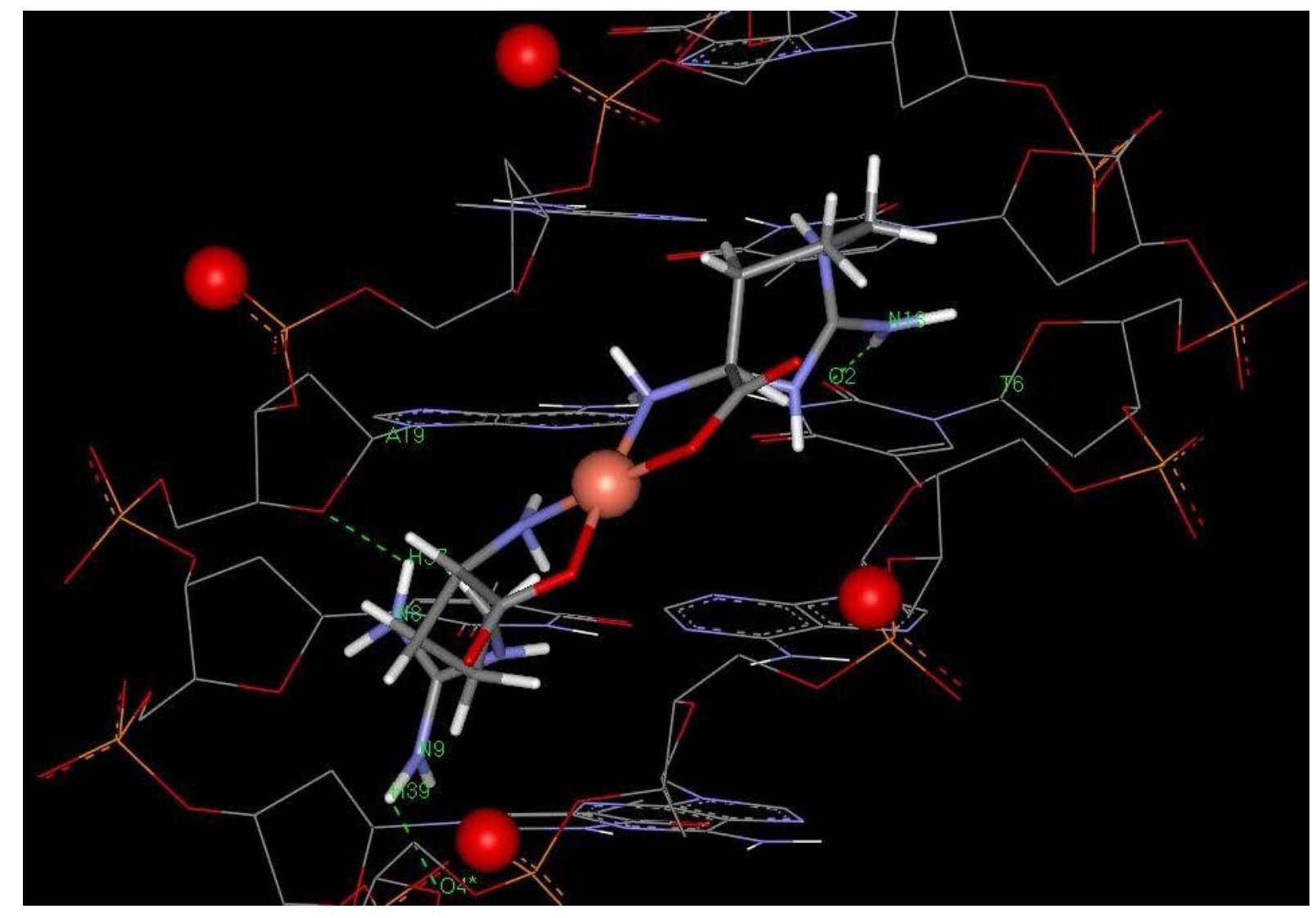

Figure S3. View of the energy minimized docked structure of $\left[\mathrm{Cu}(\mathrm{L}-\mathrm{arg})_{2}\right]^{+}(\mathbf{1})$ with $\mathrm{d}(\mathrm{CGCGAATTCGCG})_{2}$ showing hydrogen bonding interactions and electrostatic interactions between $\mathrm{Cu}^{2+}$ with negatively charged oxygen atoms from four phosphodiester backbones of d(CGCGAATTCGCG) $)_{2}$ dodecamer. 

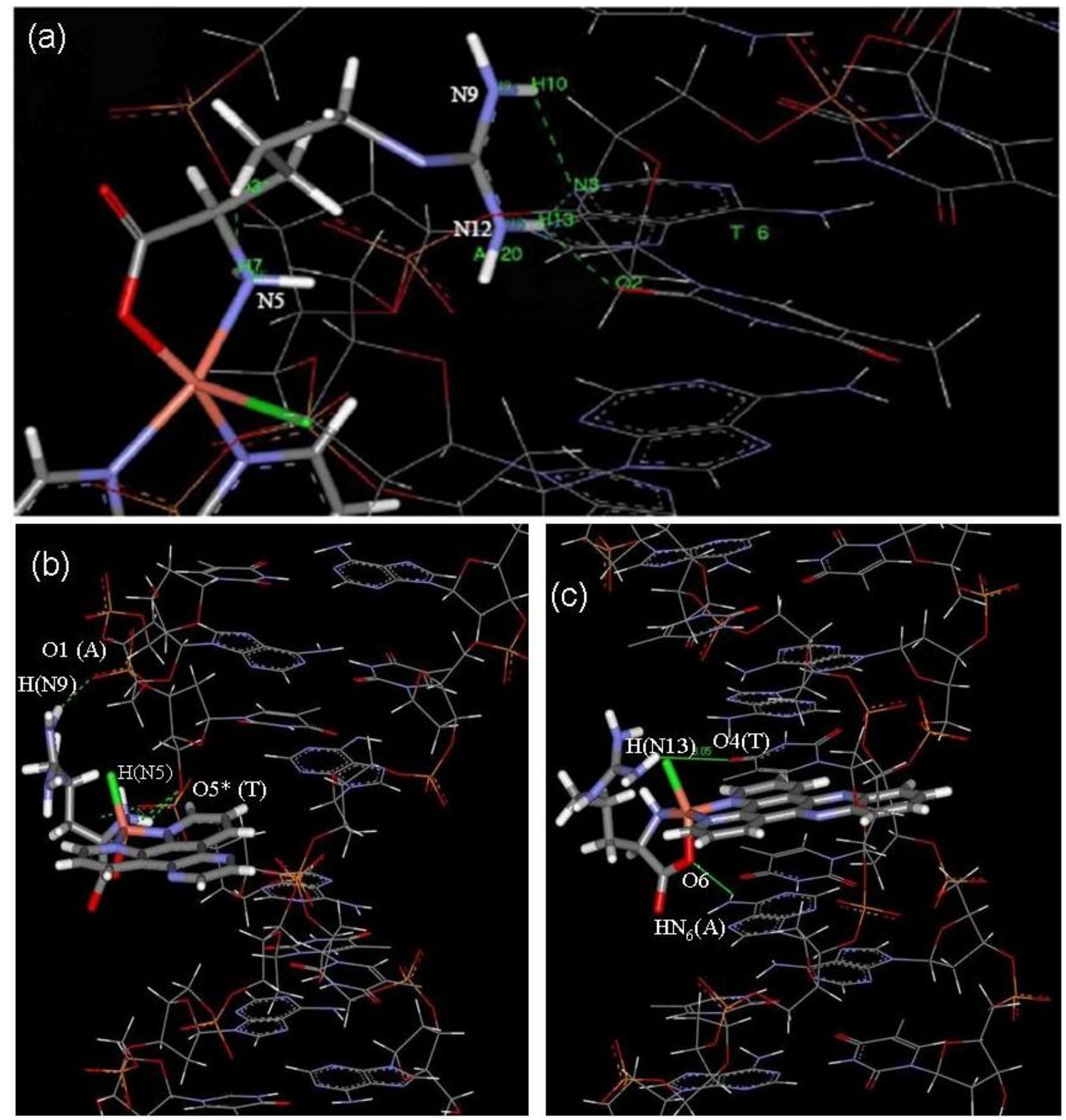

Figure S4. Views of the energy minimized docked structure of (a) $[\mathrm{Cu}(\mathrm{L}-\arg )(\text { phen }) \mathrm{Cl}]^{+}$ (3) with $\mathrm{d}(\mathrm{CGCGAATTCGCG})_{2}, \quad$ (b) $[\mathrm{Cu}(\mathrm{L}-\mathrm{arg})(\mathrm{dpq}) \mathrm{Cl}]^{+}$(4) and (c) $\left[\mathrm{Cu}\left(\mathrm{L}^{-}\right.\right.$ $\arg )(\mathrm{dppz}) \mathrm{Cl}]^{+}(\mathbf{5})$ with poly $(\mathrm{dA} \cdot \mathrm{dT})_{6}$ showing non-covalent interactions. 
Table S1. Selected Bond Distances $(\AA)$ and Angles (deg.) for $[\mathrm{Cu}(\mathrm{L}-\arg )($ phen $) \mathrm{Cl}] \mathrm{Cl} \cdot 2.5 \mathrm{H}_{2} \mathrm{O}$ $\left(\mathbf{3} \cdot 2.5 \mathrm{H}_{2} \mathrm{O}\right)$ with e.s.d.s in the Parenthesis

\begin{tabular}{|c|c|c|c|c|c|}
\hline \multicolumn{6}{|l|}{ Molecule -A } \\
\hline $\mathrm{Cu}(1)-\mathrm{O}(1)$ & $1.919(5)$ & $\mathrm{N}(1)-\mathrm{Cu}(1)-\mathrm{O}(1)$ & 166.7(2) & $\mathrm{N}(2)-\mathrm{Cu}(1)-\mathrm{Cl}(1)$ & $99.52(16)$ \\
\hline $\mathrm{Cu}(1)-\mathrm{N}(1)$ & $2.039(6)$ & $\mathrm{N}(1)-\mathrm{Cu}(1)-\mathrm{N}(2)$ & $81.5(2)$ & $\mathrm{N}(2)-\mathrm{Cu}(1)-\mathrm{N}(3)$ & $161.4(2)$ \\
\hline $\mathrm{Cu}(1)-\mathrm{N}(2)$ & $1.999(5)$ & $\mathrm{N}(1)-\mathrm{Cu}(1)-\mathrm{N}(3)$ & $99.3(2)$ & $\mathrm{N}(3)-\mathrm{Cu}(1)-\mathrm{O}(1)$ & $84.8(2)$ \\
\hline $\mathrm{Cu}(1)-\mathrm{N}(3)$ & $2.029(6)$ & $\mathrm{N}(1)-\mathrm{Cu}(1)-\mathrm{Cl}(1)$ & $93.42(17)$ & $\mathrm{N}(3)-\mathrm{Cu}(1)-\mathrm{Cl}(1)$ & $98.98(17)$ \\
\hline $\mathrm{Cu}(1)-\mathrm{Cl}(1)$ & $2.502(2)$ & $\mathrm{N}(2)-\mathrm{Cu}(1)-\mathrm{O}(1)$ & $90.6(2)$ & $\mathrm{O}(1)-\mathrm{Cu}(1)-\mathrm{Cl}(1)$ & $98.51(16)$ \\
\hline \multicolumn{6}{|l|}{ Molecule-B } \\
\hline $\mathrm{Cu}(2)-\mathrm{O}(3)$ & $1.939(5)$ & $\mathrm{N}(7)-\mathrm{Cu}(2)-\mathrm{O}(3)$ & $91.1(2)$ & $\mathrm{N}(7)-\mathrm{Cu}(2)-\mathrm{Cl}(2)$ & $98.36(17)$ \\
\hline $\mathrm{Cu}(2)-\mathrm{N}(7)$ & $2.020(6)$ & $\mathrm{N}(7)-\mathrm{Cu}(2)-\mathrm{N}(9)$ & $165.5(2)$ & $\mathrm{O}(3)-\mathrm{Cu}(2)-\mathrm{Cl}(2)$ & $100.83(16)$ \\
\hline $\mathrm{Cu}(2)-\mathrm{N}(8)$ & $2.037(5)$ & $\mathrm{N}(8)-\mathrm{Cu}(2)-\mathrm{N}(9)$ & $100.4(2)$ & $\mathrm{N}(7)-\mathrm{Cu}(2)-\mathrm{N}(8)$ & $81.4(2)$ \\
\hline $\mathrm{Cu}(2)-\mathrm{N}(9)$ & $1.993(5)$ & $\mathrm{N}(9)-\mathrm{Cu}(2)-\mathrm{O}(3)$ & $83.6(2)$ & $\mathrm{N}(8)-\mathrm{Cu}(2)-\mathrm{Cl}(2)$ & $93.28(17)$ \\
\hline $\mathrm{Cu}(2)-\mathrm{Cl}(2)$ & $2.493(2)$ & $\mathrm{N}(8)-\mathrm{Cu}(2)-\mathrm{O}(3)$ & $164.9(2)$ & $\mathrm{N}(9)-\mathrm{Cu}(2)-\mathrm{Cl}(2)$ & $95.95(17)$ \\
\hline \multicolumn{6}{|l|}{ Molecule-C } \\
\hline $\mathrm{Cu}(3)-\mathrm{O}(5)$ & $1.940(5)$ & $\mathrm{O}(5)-\mathrm{Cu}(3)-\mathrm{N}(15)$ & $84.4(2)$ & $\mathrm{N}(13)-\mathrm{Cu}(3)-\mathrm{N}(14)$ & $81.3(2)$ \\
\hline $\mathrm{Cu}(3)-\mathrm{N}(13)$ & $1.999(5)$ & $\mathrm{O}(5)-\mathrm{Cu}(3)-\mathrm{N}(13)$ & $92.9(2)$ & $\mathrm{O}(5)-\mathrm{Cu}(3)-\mathrm{Cl}(3)$ & $99.48(16)$ \\
\hline $\mathrm{Cu}(3)-\mathrm{N}(14)$ & $2.034(5)$ & $\mathrm{N}(15)-\mathrm{Cu}(3)-\mathrm{N}(13)$ & $170.7(2)$ & $\mathrm{N}(13)-\mathrm{Cu}(3)-\mathrm{Cl}(3)$ & $95.70(16)$ \\
\hline $\mathrm{Cu}(3)-\mathrm{N}(15)$ & $1.982(5)$ & $\mathrm{O}(5)-\mathrm{Cu}(3)-\mathrm{N}(14)$ & $166.2(2)$ & $\mathrm{N}(14)-\mathrm{Cu}(3)-\mathrm{Cl}(3)$ & 93.54(17) \\
\hline $\mathrm{Cu}(3)-\mathrm{Cl}(3)$ & $2.615(2)$ & $\mathrm{N}(15)-\mathrm{Cu}(3)-\mathrm{N}(14)$ & $99.3(2)$ & $\mathrm{N}(15)-\mathrm{Cu}(3)-\mathrm{Cl}(3)$ & $93.48(17)$ \\
\hline \multicolumn{6}{|l|}{ Molecule-D } \\
\hline $\mathrm{Cu}(4)-\mathrm{O}(7)$ & $1.968(5)$ & $\mathrm{O}(7)-\mathrm{Cu}(4)-\mathrm{N}(21)$ & $83.6(2)$ & $\mathrm{N}(20)-\mathrm{Cu}(4)-\mathrm{N}(19)$ & $82.0(2)$ \\
\hline $\mathrm{Cu}(4)-\mathrm{N}(19)$ & $2.029(6)$ & $\mathrm{O}(7)-\mathrm{Cu}(4)-\mathrm{N}(20)$ & $92.1(2)$ & $\mathrm{O}(7)-\mathrm{Cu}(4)-\mathrm{Cl}(4)$ & $102.00(15)$ \\
\hline $\mathrm{Cu}(4)-\mathrm{N}(20)$ & $1.987(5)$ & $\mathrm{N}(21)-\mathrm{Cu}(4)-\mathrm{N}(20)$ & $170.1(2)$ & $\mathrm{N}(19)-\mathrm{Cu}(4)-\mathrm{Cl}(4)$ & $95.95(17)$ \\
\hline $\mathrm{Cu}(4)-\mathrm{N}(21)$ & $1.982(5)$ & $\mathrm{O}(7)-\mathrm{Cu}(4)-\mathrm{N}(19)$ & $161.7(2)$ & $\mathrm{N}(20)-\mathrm{Cu}(4)-\mathrm{Cl}(4)$ & 97.33(17) \\
\hline $\mathrm{Cu}(4)-\mathrm{Cl}(4)$ & $2.613(2)$ & $\mathrm{N}(21)-\mathrm{Cu}(4)-\mathrm{N}(19)$ & $99.2(2)$ & $\mathrm{N}(21)-\mathrm{Cu}(4)-\mathrm{Cl}(4)$ & $92.35(18)$ \\
\hline
\end{tabular}



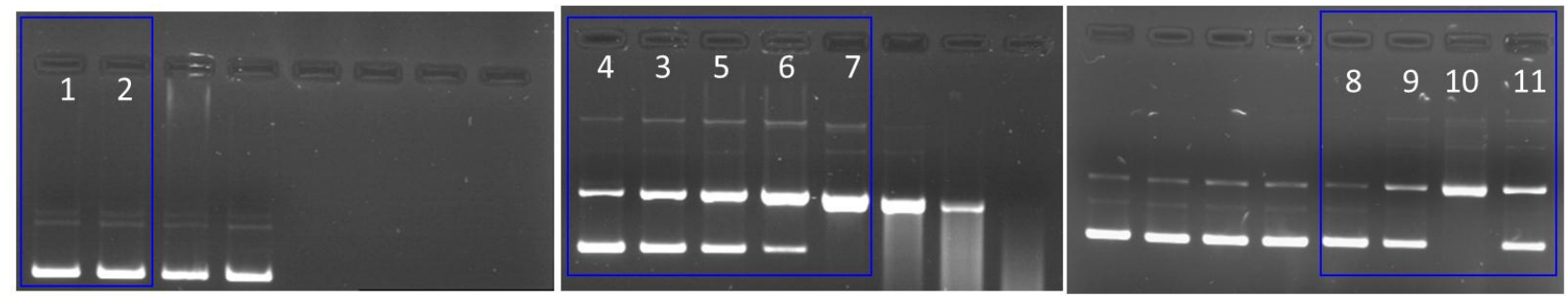

Figure S5. Gel electrophoresis diagram showing cleavage of SC pUC19 DNA $(0.2 \mu \mathrm{g}, 30 \mu \mathrm{M})$ by complexes 1-5 (5 $\mu \mathrm{M})$ in the presence of 3-mercaptopropionic acid (MPA, $0.5 \mathrm{mM}$ ) in the dark [\%NC value]: lane 1, DNA control [5]; lane 2, DNA + 3 [7]; lane 3, DNA + 1 + MPA [45]; lane 4, DNA + 2 + MPA [23]; lane 5, DNA + 3 + MPA [62]; lane 6, DNA + 4 + MPA [81]; lane 7, DNA + 5 + MPA [97]; lane 8, DNA + distamycin $(10 \mu \mathrm{M})+3$ + MPA [15]; lane 9, DNA + distamycin (10 $\mu \mathrm{M})+\mathbf{4}+$ MPA [22]; lane 10, DNA + distamycin $(10 \mu \mathrm{M})+\mathbf{5}+$ MPA [91]; lane 11, DNA + methyl green $(10 \mu \mathrm{M})+\mathbf{5}+$ MPA [31]. The lanes used to make the text Figure 7 are marked by blue color boxes.
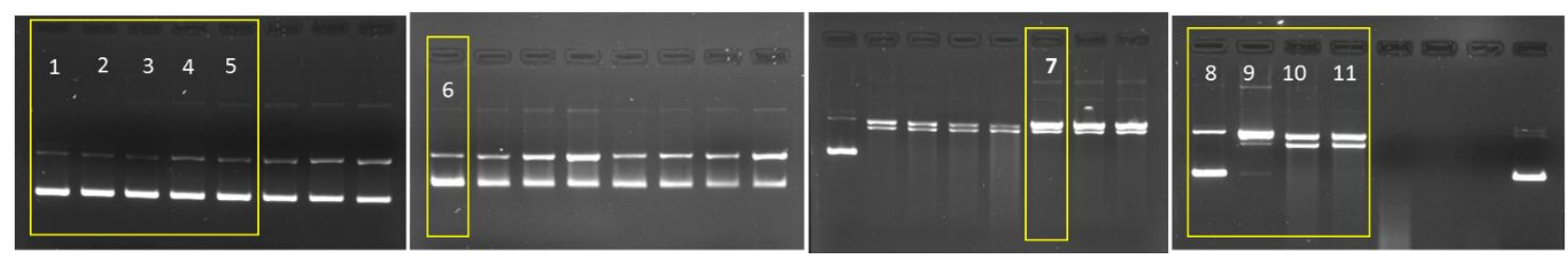

Figure S6. Gel electrophoresis diagram showing photoinduced oxidative cleavage of SC pUC19 DNA $(0.2 \mu \mathrm{g}, 30 \mu \mathrm{M})$ by netropsin (ntp, $50 \mu \mathrm{M})$ and complexes 1-5 in $50 \mathrm{mM}$ Tris- $\mathrm{HCl} / \mathrm{NaCl}$ buffer ( $\mathrm{pH}$ 7.2) on irradiation with UV-A light of $365 \mathrm{~nm}$ for $1 \mathrm{~h}$ [\% $\%$ or $\%(\mathrm{NC}+$ linear) form value]: lane 1, DNA control [5]; lane 2, DNA + 3 (dark) [5]; lane 3, DNA + L-arg (50 $\mu \mathrm{M})$ [3]; lane 4, DNA + dpq $(5 \mu \mathrm{M})$ [8]; lane 5, DNA + $\mathrm{CuCl}_{2} \cdot 2 \mathrm{H}_{2} \mathrm{O}(50 \mu \mathrm{M})[6]$, lane 6, DNA + ntp $(50 \mu \mathrm{M})$ [16]; lane 7, DNA + $1(50 \mu \mathrm{M})$ [88]; lane 8, DNA + $2(10 \mu \mathrm{M})$ [18]; lane 9, DNA + $3(10 \mu \mathrm{M})$ [93]; lane 10, DNA $+4(10 \mu \mathrm{M})$ [97]; lane 11, DNA + $5(10 \mu \mathrm{M})$ [90]. The lanes used to make the text Figure 9 are marked by yellow color boxes. 

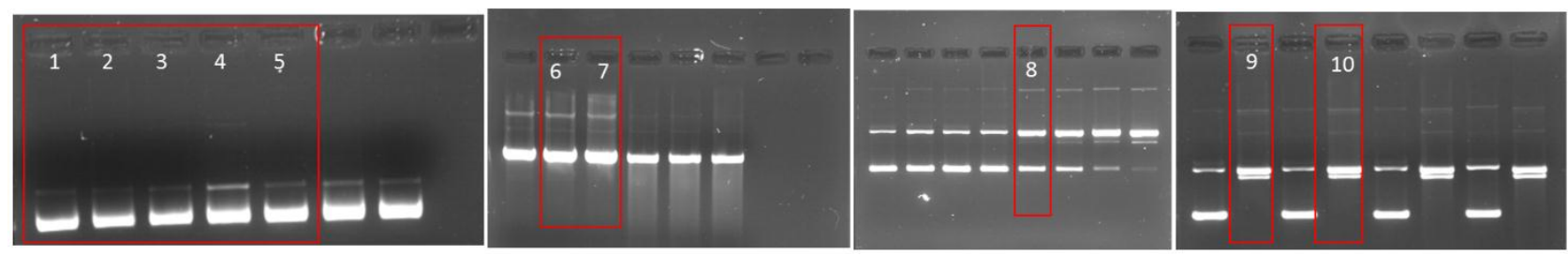

Figure S7. Red light-induced cleavage of SC pUC19 DNA $(0.2 \mu \mathrm{g}, 30 \mu \mathrm{M})$ by netropsin (ntp, 50 $\mu \mathrm{M}$ ) and the complexes $\mathbf{1 - 5}$ in $50 \mathrm{mM}$ Tris- $\mathrm{HCl} / \mathrm{NaCl}$ buffer (pH 7.2) using a 647.1 nm Ar-Kr CW laser $(100 \mathrm{~mW})$ for $2 \mathrm{~h}$ exposure time [\% $\mathrm{NC}$ or $\%(\mathrm{NC}+$ linear $)$ form value]: lane 1, DNA control [4]; lane 2, DNA + L-arg (50 $\mu \mathrm{M})$ [5]; lane 3, DNA + $\mathrm{CuCl}_{2} \cdot 2 \mathrm{H}_{2} \mathrm{O}(50 \mu \mathrm{M})$ [5]; lane 4, DNA + dpq $(10 \mu \mathrm{M})[13] ;$ lane 5, DNA + ntp $(50 \mu \mathrm{M})$ [7]; lane 6, DNA + $1(50 \mu \mathrm{M})$ [18]; lane 7, DNA + $2(50$ $\mu \mathrm{M})$ [17]; lane 8, DNA + $3(50 \mu \mathrm{M})$ [58]; lane 9, DNA + $4(10 \mu \mathrm{M})$ [98]; lane 10, DNA + $5(10$ $\mu \mathrm{M})$ [90]. The lanes used to make the text Figure 10 are marked by red color boxes.
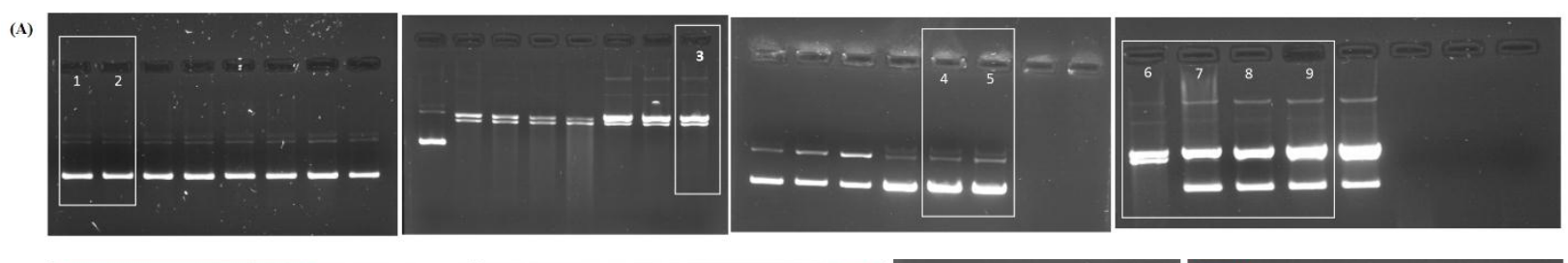

(B)
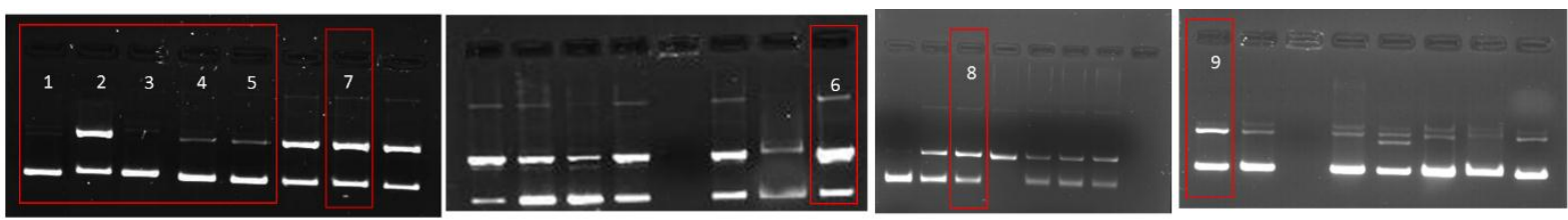

Figure S8. (A) Gel electrophoresis diagram showing the cleavage of SC pUC19 DNA (0.2 $\mu \mathrm{g}, 30$ $\mu \mathrm{M})$ by complex $1(50 \mu \mathrm{M})$ using UV radiation of $365 \mathrm{~nm}$ for $1 \mathrm{~h}$ exposure time in $50 \mathrm{mM}$ Tris$\mathrm{HCl} / \mathrm{NaCl}$ buffer $(\mathrm{pH}, 7.2)$ [\% $\mathrm{NC}$ or \%(NC + linear) form value]: lane 1, DNA control [3]; lane 2, DNA + 1 (dark) [5]; lane 3, DNA + 1 [89]; lane 4, DNA + 1 (under argon) [9]; lane 5, DNA + $\mathrm{NaN}_{3}(100 \mu \mathrm{M})+1$ [12]; lane 6, DNA + $\mathrm{D}_{2} \mathrm{O}(16 \mu \mathrm{L})+\mathbf{1}$ [99]; lane 7, DNA + DMSO $(2 \mu \mathrm{L})+\mathbf{1}$ [70]; lane 8, DNA + catalase (4 units) + 1 [73]; lane 9, DNA + SOD (4 units) + 1 [80]. The lanes used to make the text Figure 11(a) are marked by white boxes.

(B) Gel electrophoresis diagram showing photo-induced cleavage of SC pUC19 DNA (0.2 $\mu \mathrm{g}, 30$ $\mu \mathrm{M})$ by $3(50 \mu \mathrm{M})$ at $674.1 \mathrm{~nm}$ laser wavelength for $2 \mathrm{~h}$ exposure time [\% $\mathrm{NC}$ or $\%(\mathrm{NC}+$ linear) form value]: lane 1, DNA control [4]; lane 2, DNA + 3 [58]; lane 3, DNA $+\left[\mathrm{Cu}(\mathrm{phen})_{2}\left(\mathrm{H}_{2} \mathrm{O}\right)\right]^{2+}(50$ $\mu \mathrm{M}$ ) [6]; lane 4, DNA + 3 (under argon) [12]; lane 5, DNA + $\mathrm{NaN}_{3}(100 \mu \mathrm{M})+\mathbf{3}$ [16]; lane 6, DNA $+\mathrm{D}_{2} \mathrm{O}(16 \mu \mathrm{L})+3$ [74]; lane 7, DNA + DMSO $(4 \mu \mathrm{L})+3$ [52]; lane 8, DNA + catalase (4 units) + 3 [44]; lane 9, DNA + SOD (4 units) + 3 [43]. The lanes used to make the text Figure 11(b) are marked by red boxes. 